\begin{tabular}{|c|c|c|}
\hline EREM 77/2 & \multicolumn{2}{|c|}{$\begin{array}{c}\text { Urban and Environmental Quality of Subdivisions: } \\
\text { A Case of Bechar city, Algeria }\end{array}$} \\
\hline $\begin{array}{l}\text { Engineering and Management } \\
\text { Vol. } 77 \text { / No. } 2 \text { / } 2021\end{array}$ & Received 2020/12 & Accepted after revision 2021/04 \\
\hline DOI 10.5755/10.5755/j01.erem.77.2.28177 & \multicolumn{2}{|c|}{ crossef http://dx.doi.org/10.5755/j01.erem.77.2.28177 } \\
\hline
\end{tabular}

\title{
Urban and Environmental Quality of Subdivisions: A Case of Bechar city, Algeria
}

\author{
Nassira Messafri*, Abdallah Farhi
}

Department of Architecture, Faculty of Technology, Mohammed KHIDER Biskra University, BISKRA, Algeria

\section{Ratiba Wided Biara}

Departament of Architecture, Universite Tahri Mohammed de Bechar,

Avenue de l'independence, B.P 417, 08000,Bechar, Algeria

*Corresponding author: nacera.hadjer@yahoo.fr

Like any developing country, which is witnessing an exponential demographic expansion, Algeria has experienced an unsustainable housing crisis, for which subdivisions are a suitable response to the growing demand for building land. However, the intensive production effort of the housing estates has not often yielded the expected results, since this quantitative expansion, which is often unfinished, shows poor quality. However, a fairly large number of actors intervene to varying degrees, without improving the overall quality of the product. Whereas the subdivision is not just an inert urban form, conceived as a parcel division, it is rather a means of urban development that must meet the quality requirements of the living environment. In Bechar, south of Algeria, precisely, the successive production of housing estates gives today a depreciated image, reflecting an unfinished building site. This article looks for ways to improve the quality of life in these living spaces, defining the strategic principles that can promote the urban and environmental quality of subdivisions and the role of the different actors in terms of quality: from process to product. To evaluate the subdivision and promote its quality, we will adopt a site analysis grid, which will allow us to physically analyze the subdivisions, identify strengths and weaknesses with the ultimate goal of controlling impacts on the external environment, and then define strategies for a more satisfactory indoor environment than the existing one.

Keywords: subdivision, quality of life, urban dimension, environmental dimension, actors. 


\section{Introduction}

Cities are in fact constituted by assembling monuments, subdivisions and suburbs. Cities have almost always been new and most often in the form of a regular subdivision (Mangin \& Panerai, 1988). Residential subdivision has been, and continues to be, the dominant mode of settlement growth. It is one of the most appropriate built environments, where the citizen participates in the construction effort. This form of operational town planning combines the division of land ownership, its development and its use; as it dictates the construction rights in accordance with a previously established specification. It then touches on all aspects of social, economic and cultural life. These residential spaces, which at times appear as a privileged place of social consensus and at other times on the contrary as a place of conflicts, certainly play a major role in the constitution of a new type of urban configuration which is taking place at the present time(Frey, 1989).

Today, the question of subdivision arises at different scales: renovation of old fabric or peri-urban extensions. It also arises, in a wide variety of situations, as a matter of urgency in countries with high population growth, where the demand for housing is such that it is illusory to think of satisfying it by the production of buildings alone.

Like any developing country with a rapidly expanding population, Algeria (with 44.7 million inhabitants as of January 1, 2021, according to the National Investment Development Agency) has experienced an unsustainable housing crisis, for which there is such a clear demand for building land that subdivisions are a real success. Subsequently, an accelerated pace of urban growth in recent decades and new modes of urbanization characterize almost all Algerian cities; these are the ZHUN (new urban settlements) and subdivision programs. This ever-increasing trend in urbanization has brought about major physical expansions of urban regions and the replacement of natural surfaces with impervious manmade surfaces (such as concrete and asphalt) (Weng, 2012; He et al., 2014). Subdivision (the subject of this research) is among the means of responding to the emergency and the growing demand for housing. The extensions of the towns in the peripheral zones, until the beginning of the $20^{\text {th }}$ century, were essentially carried out by successive subdivisions (Saidouni,2000), which are often considered as the poor parent of urban planning (Masboungi, 2008).
Faced with this accelerated urbanization process, especially uncontrolled and often anarchic, the Algerian city is experiencing problems both in controlling and managing its growth and in the quality of its urban forms. For up to several years, populations have been plagued by these problems. It has long been said that this situation and the dissatisfaction or even rejection it aroused among the inhabitants was the consequence of the poor quality of the buildings built too quickly and cheaply under the pressure of the emergency (Mangin \& Panerai, 1988).

To this end, the successive production of subdivisions can only confer a depreciated image of urbanity and a spontaneous appropriation of space. The quantitative aspect, which to the detriment of the qualitative one offers a banal built landscape, is often at odds with the existing one; meanwhile, the local service is organized autonomously within each operation, accentuating differences and discontinuities(Mangin \& Panerai, 1999). This rupture is further accentuated by a repetitive, monotonous architecture highlighting the existence of two urban forms (that of the old fabrics and that of the subdivisions on the edge) that coexist in a non-complementary way. As a result, detached houses are rarely synonymous with urbanity, conviviality and architectural and urban quality. The process of producing a subdivision involves a fairly large number of actors who intervene to varying degrees and are increasing without improving the overall quality of the product. Probably the approach taken in the subdivision development from programming, design, and administrative compliance to implementation and management is accomplished in a linear fashion, in a process where each person's share ends when the other's share begins. This leads to confusion of roles and lack of coordination of interventions. This is what negatively affects the quality of the living environment. A simple reading of the city of Béchar allows us to note the existence of an urban landscape in socio-spatial mosaic. Several nuclei exist side by side: the traditional nucleus (ksar), the colonial nucleus, the residential subdivisions on the edge of the old districts, the large complexes built by independent Algeria, and finally the spontaneous and self-built habitat. Urban growth in this plural landscape is drivenby the urbanization subject to a demographic push, from the centre to the outskirts to the limits of the urban perimeter. In fact, it has become the preferred location 
for subserviced, virtually uncompleted subdivisions. They are displayed in all their ugliness defying the rules of art and town planning.

The aim of the work is to highlight the phenomenon of poor quality and the eternal worksite that typically shape the residential subdivisions in Bechar, the overall objective of which is to find ways to ensure the quality of life in the living spaces designated by the subdivisions. We define strategies to improve the urban and environmental quality of subdivisions by specifying the role of the different actors in the quality plan of the process to the quality of the product.

Through a literature that focuses on the concepts of quality of life in living spaces (referring here to subdivisions in their urban and environmental dimension), this study attempts to define the scope of the concept of quality of life. Quality of life is considered one of the most important dimensions for sustaining any urban development (Hamam et al., 2013).

The desire to improve the quality of life in a particular place or for a particular person or a group is an important focus of attention for planners (Lotfi \& Solaimani, 2009).Quality of life has been the focus of many studies but a consensus as to how it should be defined has not been reached. Quality of life is a complex, multidimensional (Marans, 2012) construct that requires multiple approaches from different theoretical perspectives. The standard indicators of the quality of life usually include not only wealth and employment, but also the built environment (Kahneman \& Deaton, 2010)

This covers several aspects: the natural environment (climate, state of the natural environment, etc.), the built environment (type and condition of the building, etc.), the socio-political environment (community life, citizen participation, etc.), the local economic environment (income, unemployment, etc.), the cultural and leisure environment (museums, restaurants, etc.), and the public policy environment (safety, health, education, etc.). Several studies examine the relationship between the quality of residential neighbourhoods and well-being as a major variable in quality of life indices. For example, Marans (2003) demonstrates that neighbourhood quality is important to the well-being of individuals and families. Similarly, Pacione (2003) evaluates the quality of different residential environments and emphasizes that improving the quality of housing environments means improving the well-being of individuals. Bobbitt et al.
(2005) examine the strengths and weaknesses of quality of life indices, which are based on well-being.

With reference to the work of Barbarino-Saulnier (2005), quality of life refers to both the dimensions of the material sphere and the personal sphere in their different scales. For example, materially, the quality of life is influenced both by the quality of housing and the quality of the living and social environment. At the level of the personal sphere, it is considered in relation to the needs, representations and aspirations of each person. Quality of life is considered to be a function of biophysical, environmental and social conditions (Papageorgiou, 2008). Assessing quality of life then involves interviewing individuals to identify the elements that determine their quality of life. The residents' perception of quality of life in cities is highly dependent on the choices people can actually make. These choices are strictly connected with the accessibility to services, individual allocation of time, and the social interactions people enjoy (Biagi et al., 2018).

In the same context, Sénécal et al. (2005) mention that the concept of quality of life in an urban setting refers to different aspects of urban life, like the material conditions of existence, socio-economic disparities, and organization of activities in the conurbation access to all kinds of services and equipment, or even the fact that everyone achieves their aspirations. The quality of life in an urban environment would thus be conditioned by both objective factors, such as the physical-morphological and socio-economic aspects of the urban environment, but also by the subjective dimensions of values, of everyone's perceptions and aspirations.

For Dind (2009), appreciation of the quality of life is unique to each individual, the concept of quality referring to the perceived dimension, which is eminently subjective and relative. Urban quality of life is considered a rather complex and multi-disciplinary concept with an all-inclusive perspective on social, economic, political, environmental, physical and psychological domains of a city (El Din et al., 2013). Urban environmental quality is among the prime movers of urban quality of life (Van Kamp et al., 2003; Matsuoka \& Kaplan, 2008). It is considered a proven multi-dimensional index for studying and planning in urban environments (Moore et al., 2006).

In search of conceptual precision, Chausson (2014) reveals that urban quality is not disconnected from quality of life. It is a component of it and is similar to the 
characteristics of the living environment in which individuals live. However, the assessment of quality of life cannot be limited to this component alone. The living conditions of individuals must also be taken into account. Raising the question of quality of life therefore leads to addressing urban quality. By placing the individual at the centre of the process, by questioning him/her on his/ her quality of life, theyare implicitly asked about what is important to them, about their daily needs, in relation to what it offers and what its living environment permits. If it is illusory to establish the urban qualities sought by everyone, perhaps it is more universal to know what people would like to avoid (Chausson, 2014).

\section{Methods}

To evaluate this subdivision and make it evolve into a quality subdivision, we needed a tool that would allow us to establish a diagnosis of the site during our field visits while taking into account all the fundamental issues in terms of urban and environmental quality.

Urban and environmental quality is addressed by several previous studies; for example, the research of Carmona et al. (2003) recognizes the importance of permeability, diversity, clarity and flexibility, since the quality of the urban environment should meet the following criteria: livability, individuality, character, aesthetics, connection, continuity, accessibility, visibility and diversity. Bonaiuto et al. (2003) combine the instruments of eleven scales measuring perceived environmental qualities of urban neighbourhoods and one scale measuring neighbourhood attachment. These instruments are spatial aspects (i.e., architectural/town-planning space, organization of accessibility and roads, green areas), human aspects (i.e., people and social relations), functional aspects (i.e., welfare, recreational, commercial, transport services), contextual aspects (i.e., pace of life, environmental health, upkeep and care), and neighbourhood attachment. We selected indicators to establish a subdivision analysis grid, aiming to select a representative case for its analysis, to elaborate a diagnosis taking into account a maximum of targets related to urban and environmental quality, to identify the issues at stake and finally to explain them.

We have chosen three major themes, each containing essential variables that allow us to address the crucial points to be dealt with in this subdivision and therefore to evaluate through this analysis the social, urban and environmental characteristics of our subdivisions. Through this site analysis, we aim to identify the strengths and weaknesses in order to control the impacts on the external environment and then to define strategies for a more satisfactory indoor environment than the existing one.

Our tool, the site analysis grid, allows us to physically analyze the subdivisions during our visits. It is a tool essentially based on the impressions that the different sites evoke in us, but we needed a second tool to make our analysis more efficient and sustainable. Indeed, what about the opinion of the inhabitants? Who are they? What do they do? How do they feel about their subdivision? It is a sociological questionnaire, in order to understand the qualitative aspects of our subdivisions and their inhabitants, and to understand the relationship between the designed and the lived. People vary in what they may consider to be important when judging their satisfaction with life in general and their urban quality of life in particular (Hsieh, 2003).

To prepare the main survey and the grid used in the analysis, we used the following indicators:

Social characteristics: they make it possible to determine the quality of the inhabitants (the number of people per house, their professional situation, their status, etc.). The socio-economic implications are of great importance in quality discussion that is directly related to the physical qualifications of cities (Zeren Gülersoy et al., 2009).The nature of the occupancy of dwellings, as well as their general views on the subdivision (their needs, the problems they encounter, the advantages they find in living in a single-family home, the neighbourhood, etc.).

Urban characteristics: these are questions that allow us to establish a diagnosis of the living environment, including the quality of public spaces and of pedestrian or mechanical travel, the distances travelled for daily practices, and finally to learn about the most popular modes of travel issues such as location and legibility both outside and inside the subdivisions. The proximity of public services such as schools and hospitals is an important indicator of quality of life related to housing (Streimikiene, 2015).

Environmental characteristics: integration into the environment, topography, biodiversity, climate, noise, storm water management, household waste, i.e., variables that make it possible to verify whether the developments and constructions of our subdivisions have been thoughtfully designed 
according to the constraints of the site, and its assets, which will allow us to envisage truly sustainable solutions. This part also allows us to identify the image that the inhabitants have of their neighbourhood. The indicator measuring the share of the total population exposed to the noise from neighbours or from the street represents an important issue of quality of housing environment. Pollution, grime or exposure to the other environmental problems represents the quality of housing environment and has direct impact on human health and living conditions (Streimikiene, 2015).

\section{Context of the study}

This study aims at analyzing the subdivisions of the city of Bechar (Algeria) in order to highlight their positive and negative qualitative aspects by applying a methodology.

Geographically, the Wilaya of Bechar is one of the largest Wilayas in southern Algeria (Fig.1). It covers an approximate area of $161,400 \mathrm{~km}^{2}$, or about $6.77 \%$ of the national territory, and is located in the south-west of the country. The

Fig. 1. Map of the geographical location of the Wilaya and the commune of Bechar (Bekhira et al., 2019)

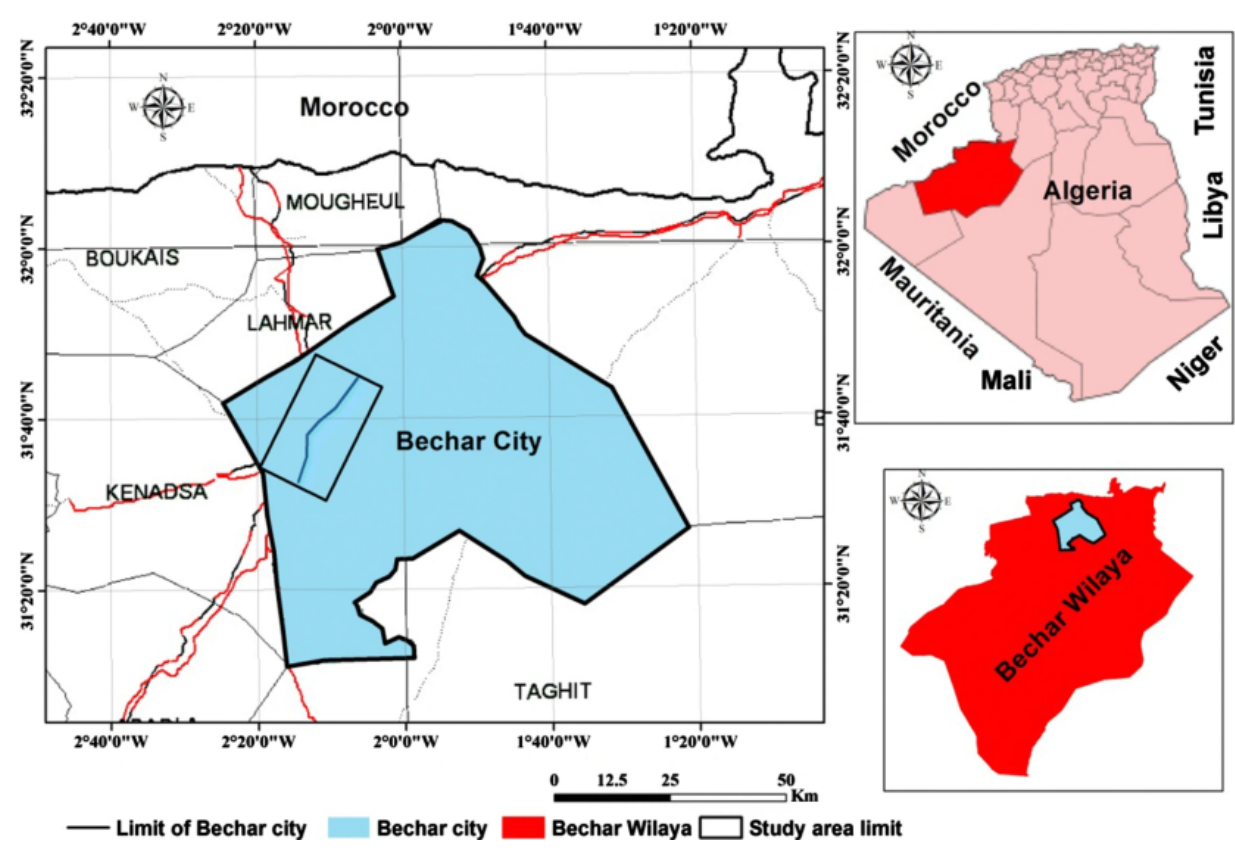

Fig. 2. Historical distribution of subdivisions in Bechar

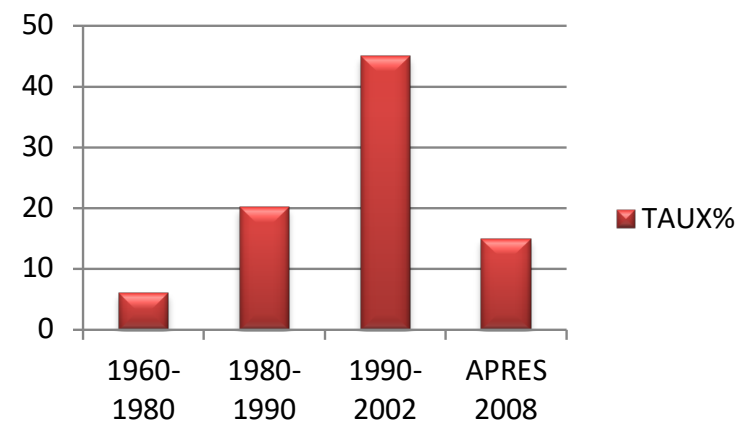

Source: prepared on the database of the Direction of Urbanism, Architecture and Construction (DUAC Bechar, Algeria, 2012) 
commune of Bechar is located in the north of its Wilaya. The city is considered as part of the Saoura region.

In order to meet housing needs, the subdivision programmes have progressively occupied all the residual spaces of the urban perimeter of the city of Bechar. They have even extended along the main arteries. The donation of these zones responds, on the one hand, to the needs of the inhabitants; on the other hand, to the economy of land reserves.

The subdivisions were established along the city's growth lines according to historical logic, between 1990 and 2002, the great boom of subdivisions in Bechar was in the period between 1990 and 2002 (Fig. 2). Local authorities have set up urban land management and regulation bodies, called land agencies, whether communal or inter municipal, or Wilaya, the latter act on their own account and on account of the local authorities. This marks the dominance of the public operator, in this case the commune and the land agency. This dominance expresses the state's monopoly on urban land management and regulation, relating to the subdivision. The private partner is timidly involved (see Table 1).

\section{The subdivision South Project: a case study}

The subdivision South Project is located in the south-western part of the city of Bechar.It occupies a total area of:14 ha. Its creation dates back to the beginning of 1996.

Table 1. Legal distribution of subdivisions in Bechar

\begin{tabular}{c|c|c|c}
\multirow{2}{*}{ Owner } & Status & $\begin{array}{c}\text { Number of } \\
\text { subdivisions }\end{array}$ & $\begin{array}{c}\text { Rate } \\
(100 \%)\end{array}$ \\
\hline \multirow{2}{*}{ Public } & Commune & 26 & \multirow{2}{*}{$93.10 \%$} \\
\cline { 2 - 3 } & AGFWB & 54 & \\
\hline Private & Private & 06 & $6.90 \%$ \\
\hline
\end{tabular}

Source: elaborated on the basis of data from the Direction of Urbanism, Architecture and Construction (DUAC Bechar, Algeria, 2012)

Fig. 3. Situation of the South Project subdivision developed on the basis of the plan development and urban planning master planof the town of Bechar

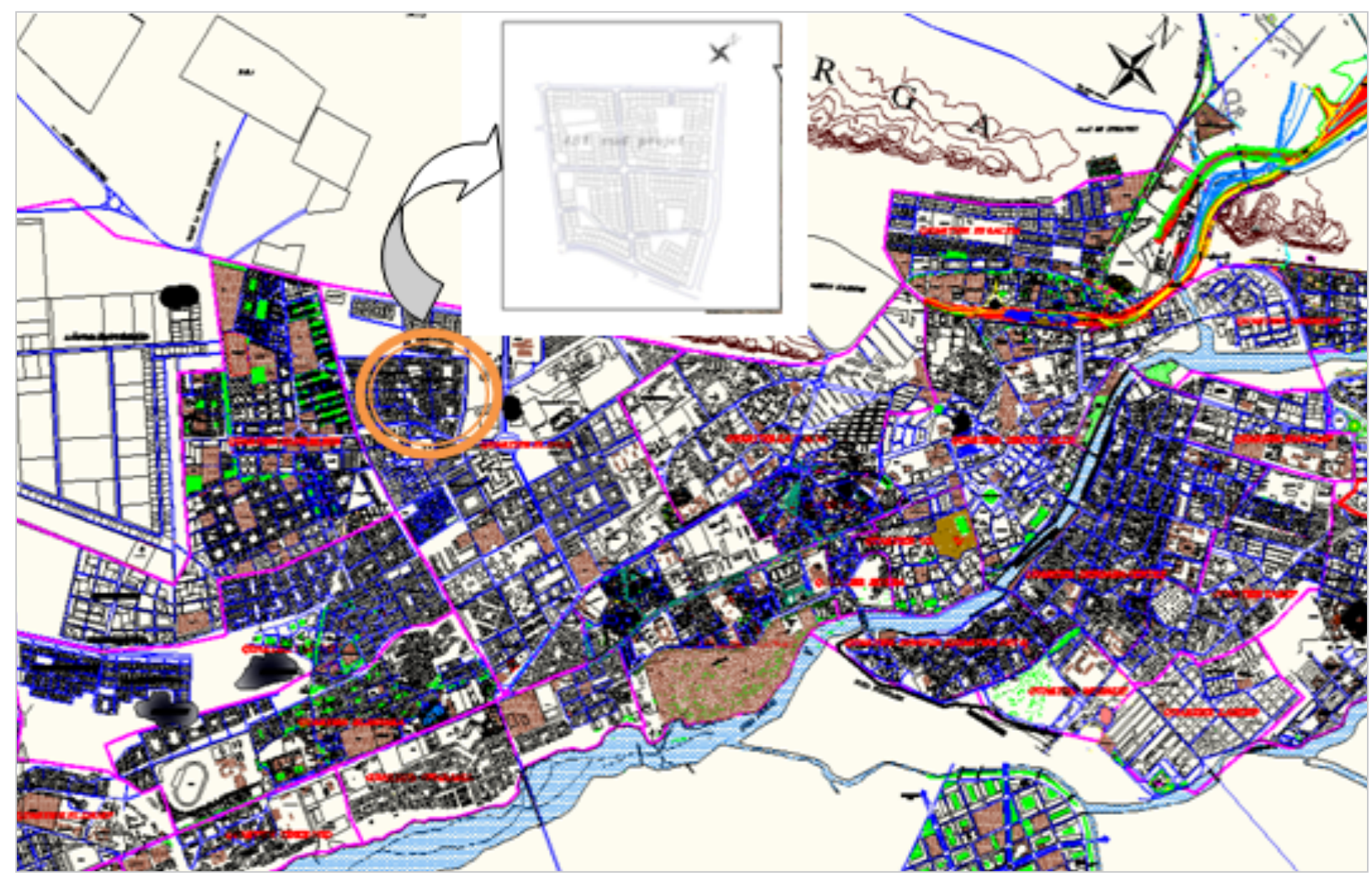




\section{Result of the analysis}

In order to assess the quality of the subdivision under study, a field survey was carried out, accompanied by onsite observation. The analysis was interpreted using a grid that classifies the results under three headings, namely social, urban and environmental characteristics. The results are presented and explained in the following tables.

Table 2. Interpretation of the results "Social characteristics"

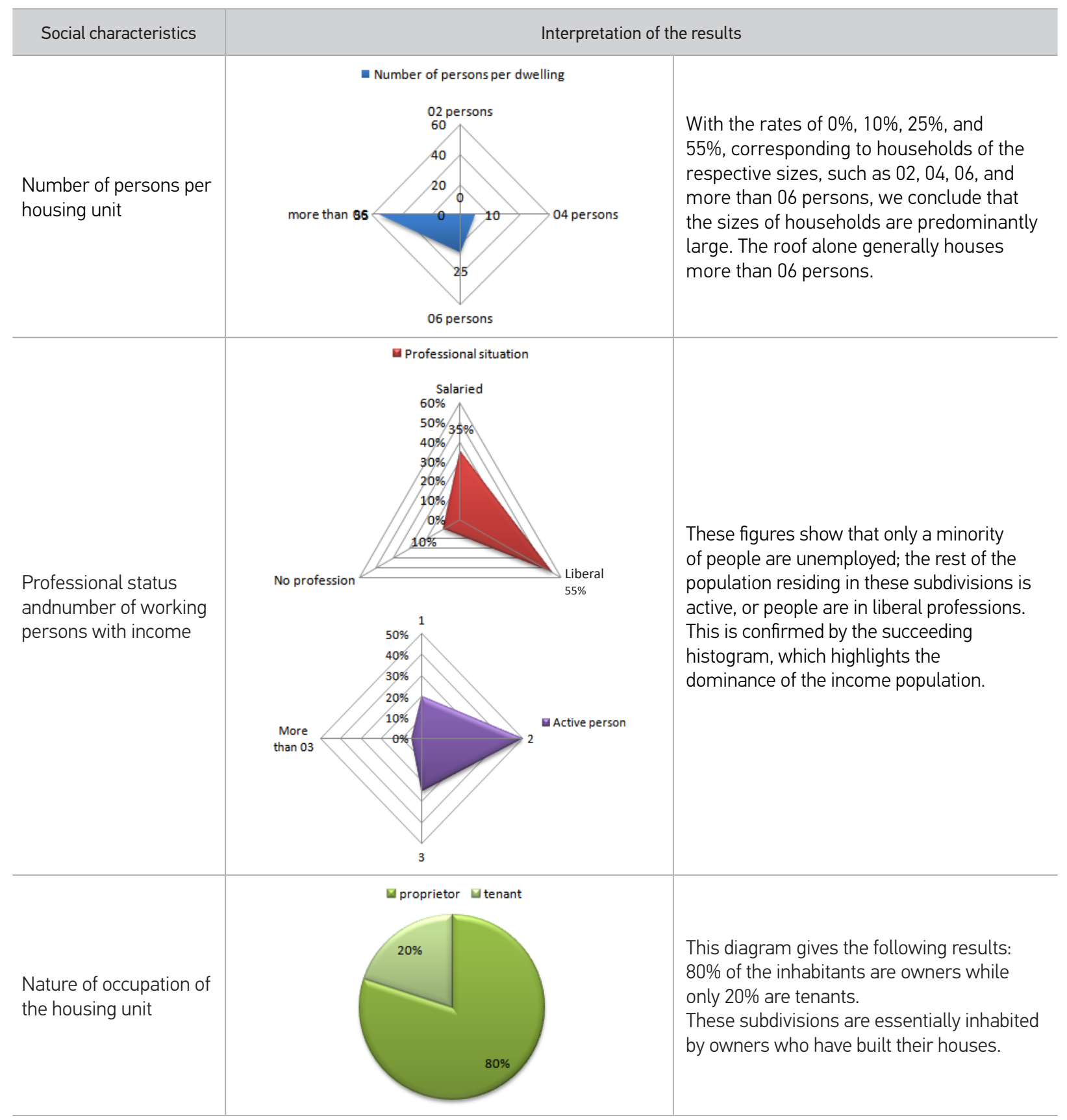


Table 3. Interpretation of the results "Urban characteristics"

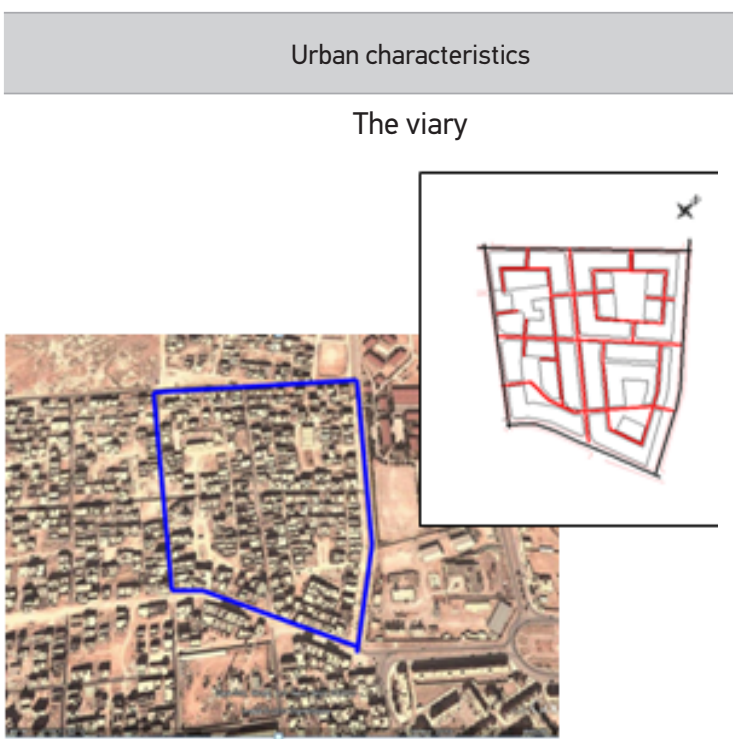

The viary weave inside the subdivision adopts an ambiguous layout that makes the reading of the fabric unreadable, even complex.

A liaison is ensured between the network of roads of the subdivision under study and that of the neighbouring fabric. It is allowed through two main paths that are perpendicular to each other and that divide the plate into two equal parts.

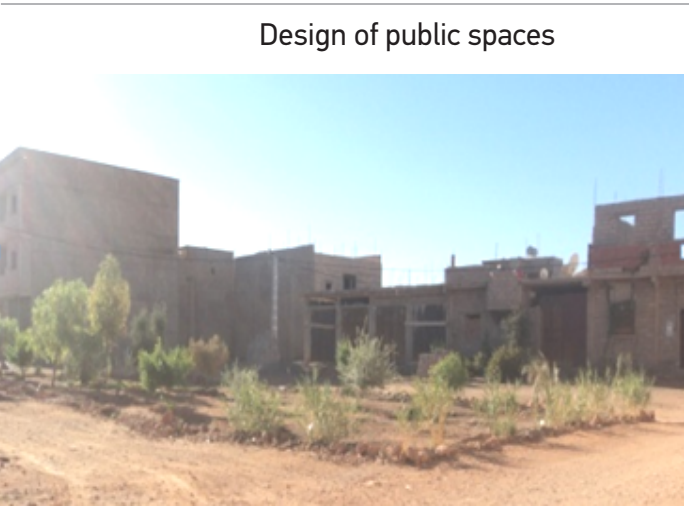

A significant percentage of the lanes are not paved or surfaced. The population mentions the lack of development of public spaces with a significant percentage of $55 \%$, while $30 \%$ complain about the unpaved roads and the non-existence of playgrounds and the tracks that were laid out and are actually in degradation.

Absence of sidewalks (only on the side of the main road). Insufficient street lighting and the total absence of other street furniture.

\section{Shape and typology of building}

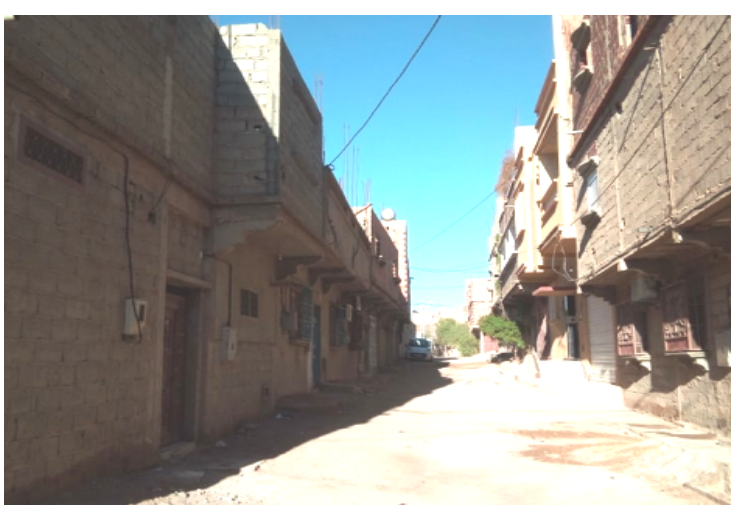

The building is linear and tends to be planar, residential type; the presence of equipment is negligible.

This subdivision ensures the alignment of the building and its respect of the direction of the track. We note the general non-completion of construction work (only $22 \%$ of the population were able to finish the building; see histogram). As a result, subdivisions remain eternal construction sites and the completion rate is insignificant, an aspect that has damaged the image of the built environment. The buildings of this subdivision consist of two types of construction: detached houses sometimes including shops, a primary school and a mosque.

No other services. 
Table 4. Interpretation of the results "Environmental characteristics"

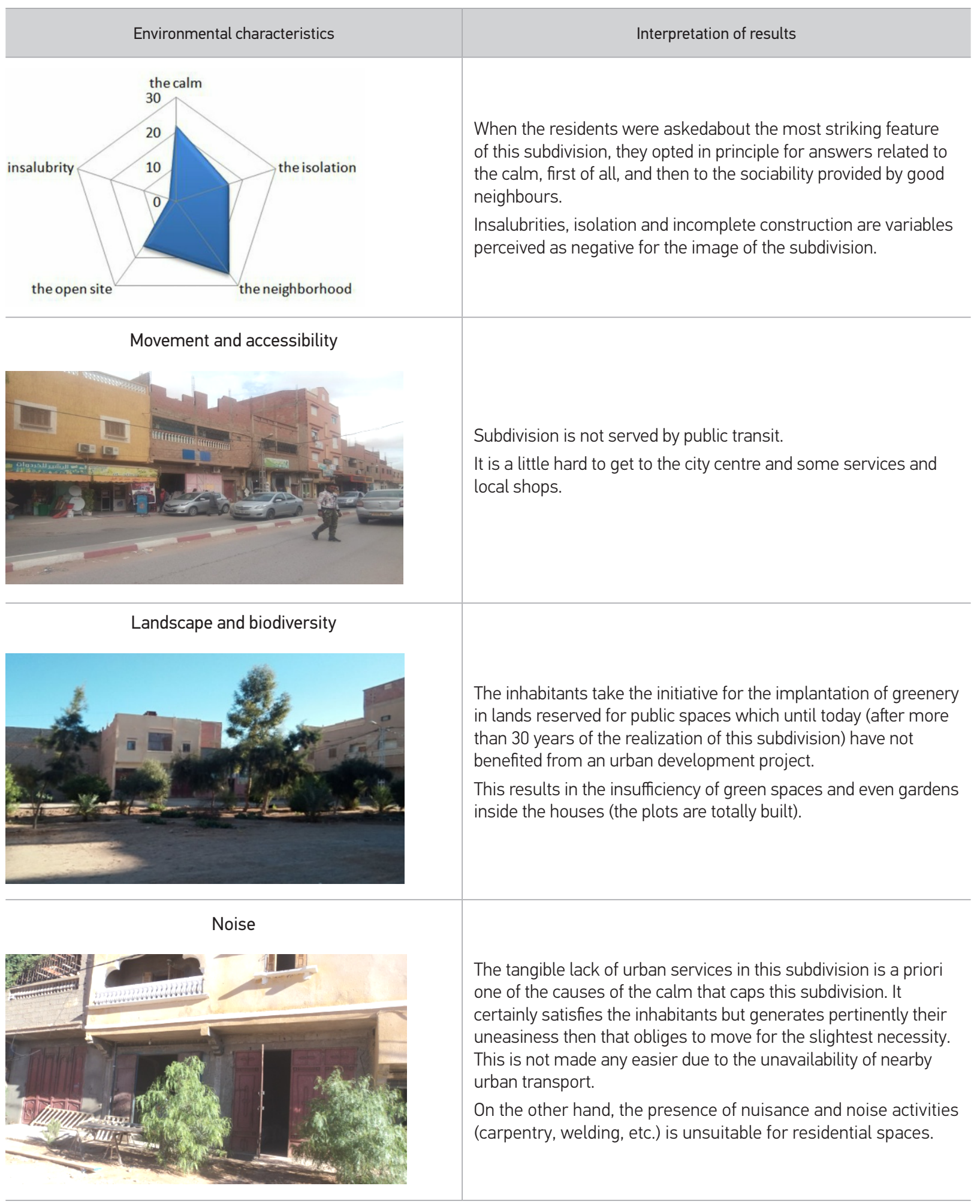


Table 4. (continued)

\begin{tabular}{|c|l}
\hline Environmental characteristics & \multicolumn{1}{|c|}{ Interpretation of results } \\
\hline Waste and storm water management & $\begin{array}{l}\text { Storage by residents and regular pick-ups, total absence of } \\
\text { selective sorting. } \\
\text { Rainwater management only by a sewerage network. }\end{array}$ \\
\hline
\end{tabular}

\section{Discussion}

Despite the dominance of the population with an income at the level of this subdivision, and regardless of the considerable accumulated income, constructions remain eternal construction sites with an insignificant completion rate, an aspect that has damaged the image of the built environment. This can be explained by several causes, the main ones beingthe incapacity of the state authorities

Fig. 4. Contracting authority, project management and use management: the actors of quality production

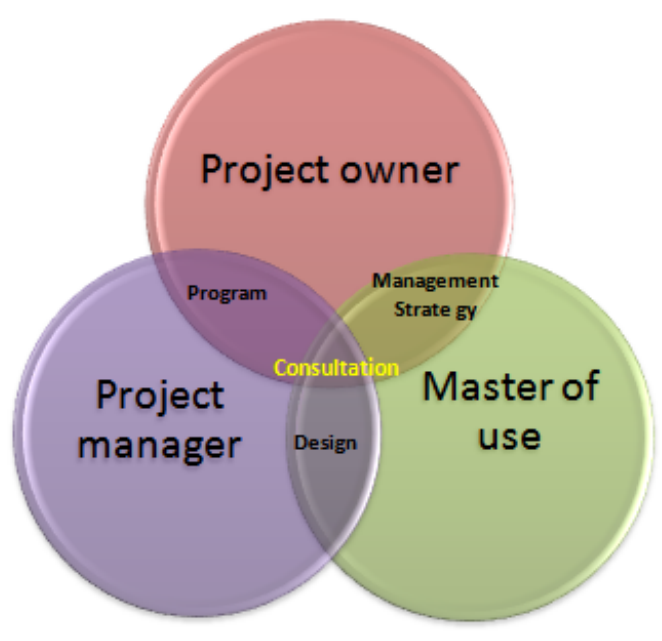

Source: Guinand and DaCunha (2014) in charge of control. Other dwellings do not have a certificate of conformity, since they have not completed their constructions. It is a deed worthy of a residence permit; sometimes you only hear about this certificate when you talk to a notary to complete the formalities of a real estate transaction. The state appears to play a passive role in this context; it is often limited to the regularization and servicing of subdivisions (water, electricity, etc.). Algeria's subdivision policy promotes efficiency over time and cost at the expense of the qualitative dimension.

The urban fabrics created by subdivisions can be considered as evolving and unfinished structures, capable of recovering unexpressed potential within the consolidated urban perimeter. The planning practices must be specified and modulated according to the contexts and scales of intervention. The projection of differentiated planning of urban spaces aims at improving the quality of the living environment of the inhabitants.

Quality is now at the forefront of the concerns of the city's various stakeholders and users and an inescapable objective of the developers, whose improvement strategies depend on skills anduser aspirations. The expectations raised by quality put public authorities at the heart of the urban production.

The relationships between the actors of quality production can be captured (Fig.4) depending on whether they 
are attached to a chain "command-conception-realization" and strategic aspects.

The creation of quality subdivisions is not a prerogative of decision-makers, elected officials and urban professionals alone. Quality requires the crossing of expert knowledge, i.e.,professional knowledge, and ordinary user knowledge. That emerges from the synergy between elected officials, designers and residents.

At the heart of the production of quality is the master of uses: the inhabitant, the user, the citizen. It is therefore necessary both to have one's skills recognized and to find a way to bring them into dialogue with the other players, from the designer to the manager.

It is through iterative consultations between project managers, contractors and users that a quality urban offer can be created, ambitious, professional and attentive to the aspirations of city dwellers capable of shaping inhabited spaces.

\section{Conclusion}

On the basis of the results of this research and with the aim of creating quality subdivisions from an urban and environmental point of view, it was necessary to incite all actors to avoid ready-made solutions, to reflect on the needs and potentialities of a place, the questions it raises, and the context in which it fits and, finally,to study it before taking action. They, therefore, aim to

\section{References}

Bekhira A., Habi M., Morsli B. (2019) The management of flood risk and development of watercourses in urban areas: case of the town of Bechar,Larhyss J 37:75-92

Barbarino-Saulnier N. (2005) From quality of life to urban diagnosis, towards a new evaluation method - The case of the city of Lyon ,Doctoral Dissertation, Lyon 2 University, Lyon.

Biagi B., GabrielaLadu M., Meleddu M. (2018) Urban Quality of Life and capabilities: An Experimental Study, Ecological Economics150: 137-152. https://doi.org/10.1016/j.ecolecon.2018.04.011

Bobbit L., Green S., Candura L. and Morgan G.A. (2005) The development of a district level index of well-being, Social Indicators Research 73: 19-42. https://doi.org/10.1007/s11205004-6165-9 define the means to achieve an essential objective: how to reconcile urban development and the quality of the living environment.

The realization of a subdivision must be based on well-considered and coherent choices with regard to the local context. This preliminary reflection is all the more necessary in the absence of an urban planning document governing the municipal territory; it must be based on a comprehensive, community-wide approach, which can take the form of a preliminary study or a communal diagnosis highlighting the weaknesses and strengths of the commune. The urban and landscape study is an essential and indispensable element to create a quality operation. This study must be entrusted to specialized professionals (architects, town planners, landscape designers, surveyors). The State is responsible for establishing and strengthening control measures to combat the scourge of illegal construction, a phenomenon that is spreading by disfiguring the image of subdivisions, a fair and equitable control regime entrusted to a corps of inspectors and urban planning police, a phenomenon that is spreading by disfiguring the image of subdivisions,

Finally, it would be advisable to start thinking about urban planning and architectural specifications adapted to this type of operation. The improvement of housing conditions in subdivisions has become an aspiration of all actors, the State as the regulator, the architect as a designer, and the user as a consumer. It is a requirement to be met, and therefore becomes the cornerstone of social and cultural development, an improvement that calls on the citizen to participate in.

Bonaiuto M., Fornara F., Bonnes M. (2003) Indexes of perceived residential environment quality and neighborhood attachment in urban environments: a confirmation study on the city of Rome, Landscape and Urban Planning65: 41-52. https://doi. org/10.1016/S0169-2046(02)00236-0

Carmona M., Heath T., Oc T., Tiesdell S. (2003) Public Places Urban Spaces: The Dimensions of Urban Design, Architectural Press, Oxford.

Chausson N. (2014). Urban quality under debate. Wht criteria for "urban quality"? Accessed January 16, 2014, Pacte Laboratory, UMR 5194, Lyon Urban Planning Agency, Lyon.

Dind J. P. (2009). Urban quality: from registers of meaning to design principles, Views of the City 22: 3-6. 
El Din H.S., Shalaby A., Farouh H.E., Elariane S.A. (2013) Principles of urban quality of life for a neighborhood. Hbrc Journal 9: 86-92. https://doi.org/10.1016/j.hbrcj.2013.02.007

Frey J-P. (1989) The housing estate: The meaning and evolution of the concept, VillesenParallèle 14:8-17. https://doi. org/10.3406/vilpa.1989.1041

Guinand S., daCunha A. (2014) Qualité urbaine, justice spatiale et projet, Presses polytechniques et universitaires romandes, Lausanne.

Hamam S.D., Shalaby A., Elsayed Farouh H., Sarah A.E. (2013) Principles of urban quality of life for a neighborhood, 09(01): 8692. https://doi.org/10.1016/j.hbrcj.2013.02.007

He C., Liu Z., Tian J., Ma Q. (2014) Urban expansion dynamics and natural habitat loss in China: a multiscale landscape perspective, Global Change Biology 20: 2886-2902. https://doi. org/10.1111/gcb.12553

Hsieh C. (2003) Counting importance: The case of life satisfaction and relative domain importance. Social Indicators Research 61: 227-240. https://doi.org/10.1023/A:1021354132664 Kahneman D. and Deaton A. (2010) High income improves life evaluation but not emotional well-being, in Proc, the National Academy of Sciences 107(38): 16489-16493. https://doi. org/10.1073/pnas.1011492107

Lotfi S., Solaimani K. (2009) An assessment of urban quality of life by using analytic hierarchy process approach, J. Soc. Sci. 5 : 123-133. https://doi.org/10.3844/jssp.2009.123.133

Madaci N. (2010) Habitat of yesterday and today between modernism and adaptation, In Proceedings of the conference on the old building: a capital to take charge of, Manteuri University, Architecture Department, Constantine, Algeria.

Mangin D., Panerai P. (1999) Urbanproject, Collection Eupalinos, Editions Parenthèse, Marseille.

Mangin D., Panerai P. (1988) The time of the city, Presses of School of architecture of Versailles, Versaille.

Marans R.W. (2003) Understanding environmental quality through quality of life studies: The 2001 DAS and its use of subjective and objective indicators, Landscape and Urban Planning, 65 (1-2): $73-$ 83. https://doi.org/10.1016/S0169-2046(02)00239-6

Marans R.W. (2012) Quality of Urban Life Studies: An Overview and Implications for Environment-BehaviourResearch, Procedia - Social and Behavioral Sciences 35: 9 - 22. https://doi. org/10.1016/j.sbspro.2012.02.058
Masboungi A. (2008) Make the city with the subdivisions, le Moniteur, Meeddat, Paris.

Moore G., Croxford B., Adams M., Refaee M., Cox T., Sharples S. (2006) Urban environmental quality: perceptions and measures in three UK cities, WIT Transactions on Ecology and the Environment 93. https://doi.org/10.2495/SC060751

Pacione M. (2003) Urban environmental quality and human well being: A social geographical perspective, Landscape and Urban Planning 65: 19-30. https://doi.org/10.1016/S01692046(02)00234-7

Papageorgiou, J.C. (2008) Quality of life indicators, International Journal Of Environmental Studies 9: 177-328. https://doi. org/10.1080/00207237608737626

Saidouni M. (2000). Elements of an introduction to town planning, Casbah edition, Algeria.

Sénécal G., Hamel, P.J., Vachon, N. (2005) Urban form, quality of life, natural and built environments: elements of reflection and test of measurement for the Montreal metropolitan region. Cahiers de géographie du Québec 49 (136): 19-43. https://doi. org/10.7202/012107ar

Streimikiene D. (2015) Quality of Life and Housing, International Journal of Information and Education Technology 5( 2). https:// doi.org/10.7763/IJIET.2015.V5.491

The Ministry of Urban Planning and Construction. (2008) Development of subdivisions -Recommendations, University Publication Office, Algiers, Algeria.

Van Kamp I., Leidelmeijer K., Marsman G., De Hollander A. (2003) Urban environmental quality and human well-being: towards aconceptual framework and demarcation of concepts; a literature study, Landscape and Urban Planning 65: 5-18. https://doi.org/10.1016/S0169-2046(02)00232-3

Van Vliet D.R. (1994) Sustainable Subdivision Planning And Design: Analysis, Literature Review And Annotated Bibliography, Urban Sustainability 7.

Weng Q. (2012). Remote sensing of impervious surfaces in the urban areas: requirements, methods, and trends, Remote Sensing of Environment 117: 34-49. https://doi.org/10.1016/j. rse.2011.02.030

Zeren Gülersoy N., Özsoy A., Tezer A., GenliYiğiter R., Günay Z. (2009) Strategic quality planning in urban environment, Istanbul Technical University 6 (1): 109-125. 